\title{
Erratum to: Single nucleotide polymorphism of toll-like receptor 4 (TLR4) is associated with juvenile spondyloarthritis in Croatian population
}

\author{
Marija Perica $^{1}$ - Mandica Vidović ${ }^{1}$ - Lovro Lamot ${ }^{1,5}$ - Lana Tambić Bukovac ${ }^{1}$. \\ Sanja Kapitanović ${ }^{2}$ - Magdalena Perić ${ }^{3}$. Jerko Barbić ${ }^{4,6}$ • Miroslav Harjaček ${ }^{1,5}$
}

Published online: 28 September 2015

(C) International League of Associations for Rheumatology (ILAR) 2015

\section{Erratum to: Clin Rheumatol}

\section{DOI 10.1007/s10067-015-2952-8}

The original version of this article unfortunately contains an error in author names. The names of the authors were inverted in the published version. The correct author name is now presented in the authorgroup and affiliation sections.

The online version of the original article can be found at http://dx.doi.org/ 10.1007/s10067-015-2952-8.

Marija Perica

marija_perica@hotmail.com

Mandica Vidović

vidovicmand@yahoo.com

Lovro Lamot

lovro.lamot@gmail.com

Lana Tambić Bukovac

lanabukovac@gmail.com

Sanja Kapitanović

kapitan@irb.hr

Magdalena Perić

magdalena0706@gmail.com
Jerko Barbić

jerko.barbic@mefos.hr

Miroslav Harjaček

miroslav.harjacek@zg.t-com.hr

1 Department of Pediatric Rheumatology, Children's Hospital Srebrnjak, Srebrnjak 100, 10000 Zagreb, Croatia

2 Ruđer Bošković Institute, Zagreb, Croatia

3 Institute for Public Health, Osijek, Croatia

4 Clinical Hospital Centre Osijek, Osijek, Croatia

5 School of Medicine, University of Zagreb, Zagreb, Croatia

6 School of Medicine, University of Osijek, Zagreb, Croatia 